\title{
THE RELATIONSHIP OF GLIOMAS WITH TP53 RS1042522 C > G AND GLIOMAS IN DUHOK
}

\author{
FARIDA F. A. NERWEYI \\ College of Nursing, University Of Duhok, Kurdistan Region-Iraq
}

(Received: October 13, 2020; Accepted For Publication: November 3, 2020)

\begin{abstract}
A tumor suppressor gene TP53 has a central role in controlling the cell cycle, apoptosis, as well as DNA damage repair. A common polymorphism in TP53 is the Arg72Pro exon 4 polymorphism. Polymorphism has been proposed to be associated with genetically determined susceptibility in different types of cancers, including glioma. This study was conducted to estimate the distribution of glioma within age groups, gender, smokers, and residence of individual also to investigate the distribution of TP53 Arg72Pro SNPs genotype in glioma, and determine whether TP53 Arg72Pro polymorphism is a possible relevance in susceptibility to glioma using RFLP-PCR analysis. Enrolled were 65 patients (glioma tissues matched age and gender) and 70 healthy individuals as a control. The findings in glioma samples 40(61.54\%) were homozygous for arginine (Arg / Arg), 19 (29.23\%) heterozygous for (Arg / Pro), and 6 (9.23\%) homozygous for proline (Pro / Pro). Three separate frequencies of genotypes of Arg72Pro; 33 $(47.14 \%), 28(40.0)$, and $9(12.86 \%)$ were identified in healthy individuals, respectively. The allele Frequencies for the Pro 72 and Arg 72 gliomas were 16 (24.62\%) and 49 (75.38\%), respectively. In the Pro 72 and Arg 72 controls, the allele frequencies were $23(32.86 \%)$ and $47(67.14 \%)$, respectively. Finally, there was no significant relationship between age group, gender, dwellers, non-smokers and smokers in different genotypes of codon 72 of TP53 gene $(P<0.05)$.
\end{abstract}

KEYWORDS: PCR- RFLP; TP53; Codon72; SNPs; Brain Cancer (Gliomas).

\section{INTRODUCTION}

I n TP53 gene, Arg72Pro polymorphism has been suggested to be associated with genetically determined susceptibility in various types of cancers including brain tumors.

In TP53 gene, Arg72Pro polymorphism has been suggested to be associated with genetically determined susceptibility in various types of cancers including brain tumors. Our objective was to investigate the possible association between TP53 Arg72Pro polymorphism with brain tumor susceptibility and to examine its correlation with the clinico-pathologic variables of tumor cases for oncologic prognosis of patients In TP53 gene, Arg72Pro polymorphism has been suggested to be associated with genetically determined susceptibility in various types of cancers including brain tumors. Our objective was to investigate the possible association between TP53 Arg72Pro polymorphism with brain tumor susceptibility and to examine its correlation with the clinicopathologic variables of tumor cases for oncologic prognosis of patients In TP53 gene, Arg72Pro polymorphism has been suggested to be associated with genetically determined susceptibility in various types of cancers including brain tumors. Our objective was to investigate the possible association between TP53 Arg72Pro polymorphism with brain tumor susceptibility and to examine its correlation with the clinico-pathologic variables of tumor cases for oncologic prognosis of patient arg72Pro polymorphism has been suggested in the TP53 gene to be associated genetically with determining susceptibility in different types of cancers including brain tumors (Sarkar et al., 2009). Variable glioma reports have been reported worldwide with inconsistent results on this polymorphism. Other polymorphic loci consequences of glioma are not much discussed (Prerana et al., 2010). In adults, gliomas account for about 2 percent of the malignant tumors. In Asia and the Pacific region, the incidence of glioma was lower than in Europe, America and Australia (Bondy et al., 2008). The etiology of brain tumors is mostly anonymous, and risk factors for brain tumors are just exposure to ionized radiation (Baldwin et al., 2004).

Studies by Sadetzki et al., (2005) and Umansky et al., (2008) have confirmed that only 
a few environmental risk factors, such as longterm ionizing radiation sequelae. An additional possible risk from low-frequency electromagnetic fields (e.g. the use of cell phones) has been proposed and lately being debated (Inskip et al., 2010; Cardis et al., 2011). Most malignancies have a higher prevalence in males than in females (Chien et al., 2016; Scarbrough et al., 2014). Whereas in Kashmir, study of Khan et al., (2015) showed no specific differences in age or gender among Brain Tumour clusters. In Sweden (1984-2005), Europe (1988-1997) and the United States (2005-2009), the average incidence rates of pediatric brain tumours were 4.2 (Lannering et al., 2009), 2.9 (Peris-Bonet et al., 2006), and 5.0 per 100,000 children up to 15 years of age (Dolecek et al., 2012). In boys, pediatric brain tumors are significantly more common than in girls. In adults, brain tumors are comparatively more common than in children; in the United States (2005-2009), for instance, there was an occurrence of $26.8 / 100,000$ in adults $(20+$ years) (Dolecek et al., 2012).

The gene TP53 located at $17 \mathrm{p} 13$, is generally known as a gene that suppresses tumors. P53 has been shown to play an important role in controlling the cell cycle, cell formation, differentiation, proliferation and apoptosis as a $53 \mathrm{kDa}$ protein encoded by the TP53 gene (Kruiswijk et al., 2015). In addition to mutations that inactivate TP53 functions, many SNPs have been specified in the TP53 that also influence the molecular function of $\mathrm{p} 53$ protein as the guardian of the genome (Yang Z et al., 2013). Arg72Pro is a polymorphism of TP53 that affects TP53's protein expression (Dastjerdi, 2011). The different outcome of $G$ to $C$ in codon 72 , which means alteration of arginine with proline (Hu et al., 2010 and Khan et al., 2015). More efficiently than the Pro72 form, the TP53 Arg72 form induces apoptosis (Dumont et al., 2003; Pim and Banks, 2004). It has been shown that more than one form of cancer is significantly associated with polymorphisms of the TP53 codon 72 gene, such as nasopharyngeal cancer (Zhuo et al., 2009), prostate cancer (Rogler et al., 2011), bladder cancer (Lin et al., 2012), lung cancer (Qiao and $\mathrm{Hu}, 2013$ ), epatocellular carcinoma, breast cancer, thyroid cancer, cervical cancer, osteosarcoma, and Wilms tumor (Rebbani et al., 2015) (Hossain et al., 2017 and Liu $\mathrm{P}$ et al., 2019).

To our Knowledge, no previous study has been reported yet in Kurdistan region of Iraq investigating the possible association between TP53 polymorphism with brain tumor susceptibility. Therefore, the present study was conducted to evaluate the distribution of glioma within age groups, gender, and individual residence in this region. The current study also seeks to determine whether SNP in TP53 may play a role in this tumor as a risk factor.

\section{MATERIALS AND METHOD}

\section{Sample collection:}

The Staff Neurosurgeons at Duhok Accident and Emergency Hospital (Teaching) collected a total of 65 samples of fresh glioma tissue from patients with brain tumors. 38 (58.5 percent) males and 27 (41.5 percent) females were included in the current investigation (Table 1). The samples were immediately put in a sterilized cup containing absolute ethanol. Tumor tissue samples were sent for histopathological diagnosis and all were diagnosed as glioma. In both groups (glioma and control), part of the infected tissue was taken and another seventy healthy individuals were enrolled as control as a source of mutant DNA. Another groups included $44(62.9 \%)$ males and $26(37.1 \%)$ females used as a category of controls (Table 1). All samples in the Duhok Governorate were taken from both rural and urban areas.

Table (1): Distribution of patients with glioma and healthy (controls) according to age groups, gender, and the inhabitants (Rural and Urban).

\begin{tabular}{|c|c|c|c|c|c|}
\hline \multirow[b]{3}{*}{ Age groups } & \multirow{3}{*}{$\begin{array}{l}\text { Characteristics } \\
20-30\end{array}$} & \multicolumn{4}{|c|}{ Study groups No. (\%) } \\
\hline & & \multicolumn{2}{|c|}{ Patients $(n=65)$} & \multicolumn{2}{|c|}{ Control $(n=70)$} \\
\hline & & 5 & 7.7 & 6 & 8.6 \\
\hline & $31-40$ & 8 & 12.3 & 10 & 14.3 \\
\hline & $41-50$ & 13 & 20.0 & 15 & 21.4 \\
\hline & $51-60$ & 17 & 26.2 & 18 & 25.7 \\
\hline & $>60$ & 22 & 33.8 & 21 & 30.0 \\
\hline \multirow[t]{2}{*}{ Gender } & Male & 38 & 58.5 & 44 & 62.9 \\
\hline & Female & 27 & 41.5 & 26 & 37.1 \\
\hline
\end{tabular}




\begin{tabular}{llllll}
\hline Smoker & Yes & 20 & 30.8 & 18 & 25.7 \\
& No & 45 & 69.2 & 52 & 74.3 \\
\hline Residence & Rural & 42 & 64.6 & 36 & 51.4 \\
(Dwelling) & Urban & 23 & 35.4 & 34 & 48.6 \\
& & & & & \\
\hline
\end{tabular}

The study was conducted at the Scientific Research Center, College of Science of Duhok University. Both tumour tissues and normal blood samples were transported to the Scientific Research Centre's medical biotechnology laboratory and Store condition $\left(\right.$ at $-8^{\circ} \mathrm{C}$ in the Freezer for example) for study. DNA was extracted (from both tumor and blood samples) using the protocol described by Maniatis et al., (1982) updated by Bass et al., (1984). The concentration and purity of the extracted DNA estimated by using the NanoDrop 1000 spectrophotometer.

All samples were subjected to PCR amplification of the Arg72Pro polymorphism region found in the TP53 gene using primers shown in Table(2) previously used by Pinto et al.,

(2008).

\begin{tabular}{|c|c|c|c|c|}
\hline \multirow{3}{*}{ Table } & $\begin{array}{l}\text { Primer of gene } \\
\text { TP53 }\end{array}$ & Sequence (5'- 3') & Length bp & Amplicon bp \\
\hline & $\begin{array}{l}\text { Arg72Pro- } \\
\text { Forword }\end{array}$ & 5'- GAA GAC CCA GGT CCA GAT GA-3' & 20 & 152 \\
\hline & $\begin{array}{l}\text { Arg72Pro- } \\
\text { Reverse }\end{array}$ & 5'- CTG CCC TGG TAG GTT TTC TG-3' & 20 & \\
\hline
\end{tabular}

(2):

Primers that used for amplification of TP53 gene codon72 Arg72Pro SNPs

\section{Polymerase chain reaction $(\mathbf{P C R})$ :}

TP53 Arg72Pro polymorphism detection was performed by PCR-RFLP. For amplification in a $25 \mu L$ reaction mixture, the genomic DNA (100 ng) template was used, For amplification, the Cinagen PCR ready master mix kit was used as follows: $12.5 \mu L$ Master mixture, $8.5 \mu L$ D.D.W, $1 \mathrm{uL}$ Forward primer, $1 \mathrm{uL}$ Reverse primer $1 \mathrm{uL}$. The amplification conditions were as follows; first step calling pre-PCR at $95^{\circ} \mathrm{C}$ for $5 \mathrm{~min}$ denaturation, then applying 35 cycles at $94{ }^{\circ} \mathrm{C}$ for $30 \mathrm{~s}$. denaturation, $54^{\circ} \mathrm{C}$ for $30 \mathrm{~s}$. annealing, $72{ }^{\circ} \mathrm{C}$ for $30 \mathrm{~s}$. extension, and $5 \mathrm{~min}$. extension as a final step within $72^{\circ} \mathrm{C}$. After running the product bands visualized by UV light, PCR products were run on 2 percent agarose electrophoresis (Pinto et al., 2008).

\section{Analyzing RFLP:}

The TP53 Arg 72Pro SNP amplicons were digested overnight with BstU I restriction enzymes at $37^{\circ} \mathrm{C}$ (Fermentas, Germany). After ethidium bromide staining, the effects of enzymatic digestion were visualized by UV light in a 3 percent agarose gel by electrophoresis.

\section{DATA ANALYSES}

The characteristics of the patients and control groups were presented by percentage and number in a Pearson Chi-squared test, then compared. The comparison of allele and genotype prevalence between controls and patients. The relevant difference amount was estimated with a P-value of less than 0.05. Statistical studies were carried out using the version 25 social science statistics kit (IBM SPSS Statistics for Windows, Version 25.0. Armonk, NY: IBM Corp).

\section{RESULTS}

The samples in the current study were composed of 65 cases of new brain tumor tissues, all of which were histopathologically diagnosed as glioma, and 70 healthy cases as a 
control. The distribution of samples according to the gender for patient cases were 38 (58.5 percent) males and 27 (41.5 percent) females (M / $\mathrm{F}$ ratio $=1.41)$. The mean age was 43 years (range 22-64. Whereas, the healthy control blood samples consisted of $44(62.9 \%)$ males and $26(37.1 \%)$ females $(\mathrm{M} / \mathrm{F}=1.7)$, the mean age was 46 years (range $=25-67$ years). There were no variations in age and gender differences ( $p>0.05)$ observed among were glioma patients. The patients 20 smokers and 45 non-smokers, while the control groups were 18 smokers and 52 non-smokers, respectively. The findings of the statistical in the present study showed that there was no substantial difference $(p>0.05)$ in the smoking status of patients with glioma and of individuals in the control group, as well as in the residence status (rural or urban) of individuals (Table 3).

\section{Analyzing PCR:}

Both sample groups, 65 glioma and 70 controls, were successfully amplified and polymorphic alleles were analysed for TP53 codon 72 . The results of $152 \mathrm{bp}$ amplicon is shown in Figure 1.

Table (3): Comparison of general characteristics of patients with glioma and healthy controls

\begin{tabular}{|c|c|c|c|c|c|c|}
\hline \multirow{2}{*}{ Characteristics } & & \multicolumn{4}{|c|}{ Study groups No. (\%) } & \multirow[t]{2}{*}{ P-value } \\
\hline & & \multicolumn{2}{|c|}{ Patients $(n=65)$} & \multicolumn{2}{|c|}{ Controls $(n=70)$} & \\
\hline \multirow[t]{5}{*}{ Age groups } & $20-30$ & 5 & 7.7 & 6 & 8.6 & \\
\hline & $31-40$ & 8 & 12.3 & 10 & 14.3 & \\
\hline & $41-50$ & 13 & 20.0 & 15 & 21.4 & 0.988 \\
\hline & $51-60$ & 17 & 26.2 & 18 & 25.7 & \\
\hline & $>60$ & 22 & 33.8 & 21 & 30.0 & \\
\hline \multirow[t]{2}{*}{ Gender } & Male & 38 & 58.5 & 44 & 62.9 & \\
\hline & Female & 27 & 41.5 & 26 & 37.1 & 0.601 \\
\hline \multirow[t]{2}{*}{ Smoker } & Yes & 20 & 30.8 & 18 & 25.7 & \\
\hline & No & 45 & 69.2 & 52 & 74.3 & 0.514 \\
\hline Residence & Rural & 42 & 64.6 & 36 & 51.4 & \\
\hline (Dwelling) & Urban & 23 & 35.4 & 34 & 48.6 & 0.121 \\
\hline
\end{tabular}

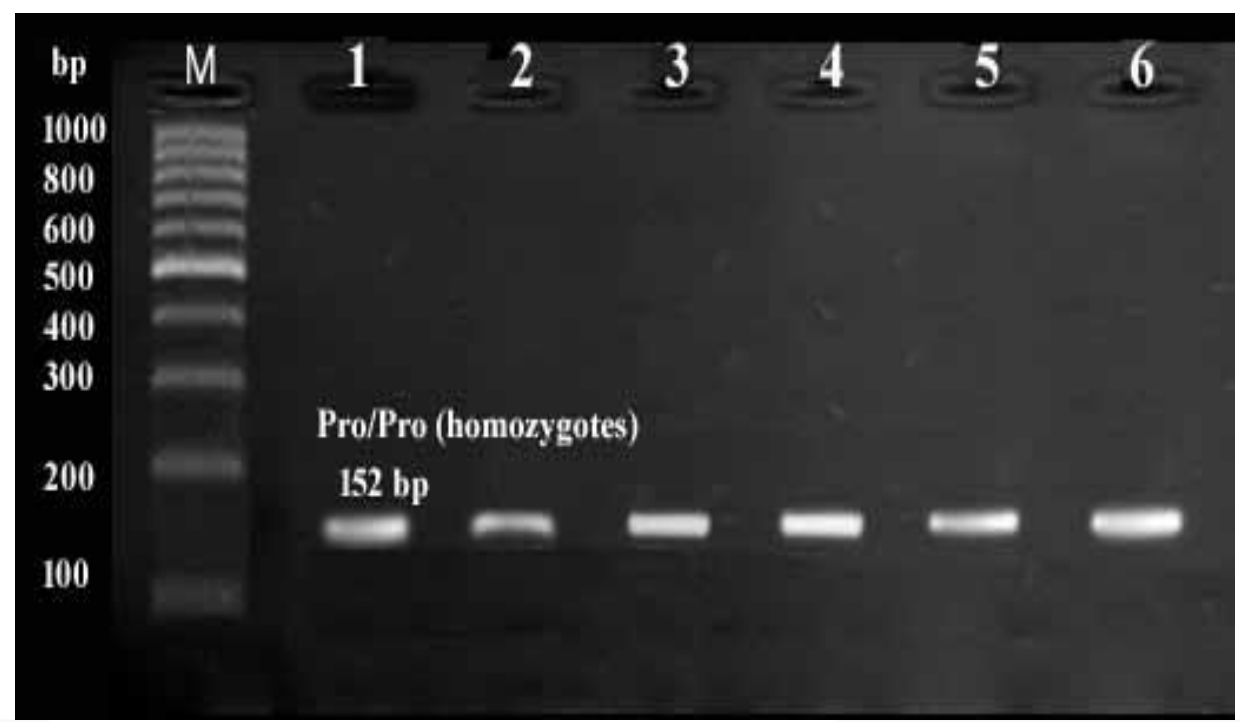

Fig. (1): Represent the amplicon bands of TP53 Arg72Pro SNPs by 2\% agarose gel electrophoresis. 


\section{Analyzing RFLP:}

With the BstU I restriction enzyme, the amplified fragments of TP53 Arg 72Pro SNP were digested (Figure 2). The findings were that a single band (152 bp) indigested PCR product identified as the Pro/Pro variant (CC) representing homozygotes proline, two fragments of 50 and $102 \mathrm{bp}$ representing homozygotes arginine (Arg/Arg) wild (GG), and heterozygotes for codon $72 \mathrm{Arg} / \mathrm{Pro}$ variant (GC) identified by three fragments representing 50, 102 and 152 bp (Khan et al., 2015).

The current research showed 6 (9.23\%) glioma patients with 152 bp undigested PCR product fragment representing homozygotes proline (Pro / Pro), 40 (61.54\%) with two 50 and $102 \mathrm{bp}$ fragments representing homozygotes arginine (Arg / Arg), and 19 (29.23\%) with three 50,102 , and 152 bp fragments representing heterozygotes for codon 72 (Arg / Pro).

Results of control genotypes showed 9 $(12.86 \%)$ individuals with a fragment of $152 \mathrm{bp}$ representing homozygotes proline (Pro/Pro), 33 $(47.14 \%)$ with two fragments representing homozygotes arginine (Arg / Arg), and 28 $(40.0 \%)$ with three bands representing heterozygotes (Arg / Pro) for codon 72 (Table 4) (Figure

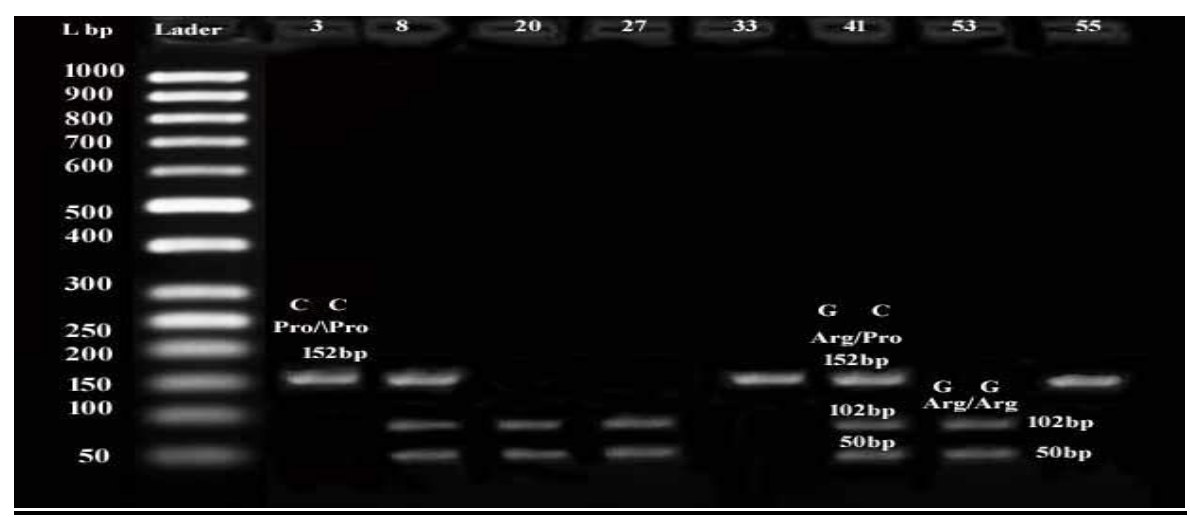

Fig. (2): PCR- RFLP study illustrates TP53 codon 72 SNPs by electrophoresis of agarose gel (3\%). After digestion, PCR products are shown: samples 3, 33 and 55, Pro / Pro (CC); samples 20, 27 and 53, Arg / Arg (GG); and samples 8 and 41, Arg / Pro (GC), markers of 50 bp DNA scale.

Table (4): Comparison of prevalence of allele and genotype between controls and patients.

\begin{tabular}{|c|c|c|c|c|c|c|}
\hline & \multirow[t]{2}{*}{ Genotypes } & \multicolumn{4}{|c|}{ Study groups No. (\%) } & \multirow[t]{2}{*}{ P-value } \\
\hline & & \multicolumn{2}{|c|}{ Patients $(n=65)$} & \multicolumn{2}{|c|}{ Controls $(n=70)$} & \\
\hline & \multicolumn{6}{|l|}{ TP53 Arg72Pro } \\
\hline & Arg/Arg & 40 & 61.54 & 33 & 47.14 & \\
\hline & Arg/Pro & 19 & 29.23 & 28 & 40.0 & 0.245 \\
\hline & Pro/Pro & 6 & 9.23 & 9 & 12.86 & \\
\hline & \multicolumn{6}{|l|}{ Allele frequency } \\
\hline & Arg72 allele & 49 & 0.75 & 47 & 0.67 & 0.291 \\
\hline & Pro 72 allele & 16 & 0.25 & 23 & 0.33 & \\
\hline & \multirow[t]{2}{*}{ Genotype/Allele } & \multicolumn{4}{|c|}{ Study groups No. (\%) } & P-value \\
\hline Characteristics & & \multicolumn{2}{|c|}{ Patients $(n=65)$} & \multicolumn{2}{|c|}{ Controls $(n=70)$} & \\
\hline \multirow[t]{6}{*}{ Male (p.n=38, c.n=44) } & Arg/Arg & 28 & 0.73 & 33 & 0.75 & \\
\hline & Arg/Pro & 8 & 0.21 & 8 & 0.18 & 0.791 \\
\hline & Pro/Pro & 2 & 0.05 & 3 & 0.07 & \\
\hline & Allele frequency & & & & & \\
\hline & Arg72allele & 32 & 0.8 & 37 & 0.84 & 0.597 \\
\hline & Pro72allele & 6 & 0.2 & 7 & 0.16 & \\
\hline \multirow{3}{*}{$\begin{array}{l}\text { Female }(p . n=27, \\
\quad \text { c. } n=26)\end{array}$} & Arg/Arg & 12 & 0.44 & 9 & 0.35 & \\
\hline & Arg/Pro & 11 & 0.41 & 15 & 0.57 & 0.293 \\
\hline & Pro/Pro & 4 & 0.15 & 2 & 0.08 & \\
\hline
\end{tabular}




\begin{tabular}{llllll} 
Allele frequency & & & & & \\
Arg72allele & 19 & 0.7 & 17 & 0.6 & 0.340 \\
Pro72allele & 9 & 0.3 & 9 & 0.4 & \\
\hline
\end{tabular}

The findings of the current study indicate that there are no substantial variations $(\mathrm{P}>0.05)$ in the frequency of Pro72allele in patients as compared to control groups. Similarly, with regard to the frequency of the Arg72allele, there are no substantial variations $(P>0.05)$ between the frequency of the Arg72allele in control group patients (Table 4).

The current research indicates no substantial differences $(\mathrm{P}>0.05)$ between the frequency of and Pro72allele in glioma-affected females as opposed to the frequency of Arg72allele and Pro72allele in the control groups. In relation to the frequency of Arg72allele and Pro72allele in males, the same result is shown (Table 4).

Fig. (3): Frequencies of allele and genotype between controls and patients.

\section{DISCISSION}

Single Nucleotide polymorphisms are considered very important common modifications in human DNA and have been frequently studied in the search for genetic predisposition of various diseases, because they are not time consuming with low cost and reliable outcomes of supply. The detection of these nucleotides in human DNA may be considered risk factors and in patients with malignancies may help diagnosis and follow-up. The role of these SNPs as risk factors that could influence prevention, diagnosis and also as a prognostic factor has been stated by Kirk et al., (2002).

The current study shows that no clear gender, age, smoking status and residential (rural or urban) variations $(\mathrm{P}<0.05)$ between the glioma groups (Table 3). Khan et al., (2015) Kashmir study showed the same outcome as that found in the current study, with no major variations between age groups or gender in Brain Tumor patients. Likewise, no major difference in dwelling and smoking status was seen. Previous studies have shown that brain tumours vary according to gender, age, ethnicity, and geography. In Sweden (1984-2005), Europe (1988-1997) and the United States (2005-2009), the average incidence rates of pediatric brain tumours were 4.2 (Lannering et al., 2009), 2.9 (Peris-Bonet et al, 2006), and 5.0 per 100,000 children up to 15 years of age (Dolecek et al, 2012).

In boys, pediatric brain tumors are significantly more common than in girls. Brain tumors are relatively more common in adults than in children; the incidence in adults $(20+$ years) was $26.8 / 100,000$ in the United States (2005-2009), for example (Dolecek et al., 2012). No association between cigar smokers and glioma disease was shown in the Baldwin et al (2004) study. The etiology of brain tumors remains largely unknown, with exposure to ionizing radiation being the only reported risk factors for brain tumors (Baldwin et al., 2004). Studies by Sadetzki et al., (2005) and Umansky et al., (2008) have confirmed that only a few 
environmental risk factors, such as long-term ionizing radiation sequelae, have been identified. An additional possible risk (e.g. cell phone use) from low-frequency electromagnetic fields has been proposed and is currently under consideration (Inskip et al., 2010; Aydin et al., 2011; Cardis et al., 2011).

TP53 codon 72 genotypes $9.23 \%$ glioma patients as a proline homozygote (Pro / Pro), while the same genotype showed in $12.86 \%$ healthy individuals in control groups. Arginine homozygotes (Arg / Arg) was 61.54\%, while $47.14 \%$ individuals in control groups. Heterozygotes (Pro / Arg) for the codon 72 gene, was $29.23 \%$, while $40.0 \%$ individuals in controls $(\mathrm{P}=0.245)$. No substantial differences $(\mathrm{P}<0.05)$ have been reported in all genotypes, as well as in the allele frequencies between glioma patients and control groups. This results In agreement with the study Hamajima et al., (2002), they found that the TP53 codon 72 gene polymorphism in patients with colorectal cancer was not significantly associated with the same codon polymorphism in a normal person in Japan. The stomach polymorphism analysis by Khadand et al., (2007) also showed nonsignificant variations in genotype frequencies and allele frequencies of TP53 Arg72Pro, colorectal adenocarcinoma and breast cancer patients when compared with healthy people in the Southern Iran population. The same findings suggest no connection between TP53 Arg 72 Pro polymorphism and glioma cancer when examined in the Southeast Brazilian population (Pinto et al., 2008). The study conducted by Onrat et al., (2009) in Turkey and Japan did not find a correlation between the prevalence of TP53 gene polymorphism with colorectal cancer, and their study showed that the frequency of alleles was consistent between the control group and colorectal cancer cases.

The study by Khan et al., (2015) of Proline allele in the TP53 gene, Arg72Pro polymorphism in a Kashmir population, showed that no statistical difference was observed between patients and the control group in the TP53 gene, Arg72Pro polymorphism. Moradinasab et al., (2017) showed no major connection between breast cancer and codon 72 polymorphism in TP53. Fang et al., (2020) found that there was no important link between TP53 gene polymorphism and neuroblastoma susceptibility.

Another report disagrees with the current study's outcome. A research conducted by Zhou et al ., (2009) concluded that TP53 Arg 72 Pro SNP is a risk factor for the development of many cancers, including cervical head and neck, colorectal, breast cancers and many others. Similarly, the molecular genetic analysis by Mammano et al., (2009) found that the genetic risk factor for colorectal cancer was codon 72 polymorphism, the genotype frequencies of TP53 codon 72 in patients with sporadic colorectal adenocarcinomas and normal individuals from the Isfahan province of Iran in 2008 showed a substantial difference between the controls and the Arg / Arg genotype case group compared to Arg / Pro genotype.

Study of Doosti et al, (2011) in the colorectal cancer population of South West Iran, which reported that the TP53 codon 72 genotype frequencies among the cases and control groups were not closely consistent with the HardyWeinberg equilibrium rule and their outcome showed substantial differences in allele and genotypic frequencies between control groups and patients. Their findings also showed a decline in the homozygous genotype of Proline and a rise in patients' homozygous genotypes of Arginine and an increase in the frequency of Arg allele. There is no research conducted with distinct genetic analysis in general that has shown a clear correlation and it is still elusive (Khadang et al., 2007).

\section{CONCLUSION}

Based on our observations, we may conclude that there is no association between TP53 Arg72Pro and increased glioma susceptibility in Duhok / Iraq.

\section{REFERENCES}

Mamelak, A.N., and Jacoby, D.B., (2007). "Targeted delivery of antitumoral therapy to glioma and other malignancies with synthetic chlorotoxin (TM-601)". Expert Opinion on Drug Delivery. 4 (2), 175-186.

Sarkar, C., Jain, A., and Suri, V., (2009). Current concept in the pathology and genetics of glioma. Indian journal of cancer. 49(2), 108119.

Prerana, J.h.a., Pankaj, J.h.a., Pankaj, P., Kunzang, C., Vaishali, S., Mehar, C.S., Guresh K., Manmohan, S., Ashok Kumar, M., Chitra S., (2011). TP53 polymorphisms in gliomas from Indian patients: Study of codon 72 genotype, rs1642785, rs1800370 and 16 base pair insertion in intron-3. Exp Mol Pathol. 90(2), 167-72. 
Bondy, M.L., Scheurer, M.E., Malmer, B., BarnholtzSloan, J.S., Davis, F.G., Il'yasova, D., Brain Tumor Epidemiology, C. (2008). Brain tumor epidemiology: consensus from the Brain Tumor Epidemiology Consortium. Cancer. 113(7 Suppl), 1953-1968.

Baldwin, R.T., and Preston-Martin S., (2004). Epidemiology of brain tumors in childhood--a review. Toxicol Appl Pharmacol. 199(2), 11831.

Sadetzki, S., Flint-Richter, P., Starinsky, S., Novikov, I., Lerman, Y., Goldman, B., et al (2005). Genotyping of patients with sporadic and radiation-associated meningiomas. Cancer Epidemiol Biomarkers Prev. 14, 969-76.

Umansky, F., Shoshan, Y., Rosenthal, G., Fraifeld, S., Spektor, S., (2008). Radiation-Induced Meningioma. Neurosurg Focus. 24 (5), E7.

Inskip, P.D., Hoover, R.N., Devesa, S.S., (2010). Brain cancer incidence trends in relation to cellular telephone use in the United States, Neuro Oncol. 1211, 1147-1151.

Cardis, E., and Sadetzki, S., (2011). Indications of possible brain-tumour risk in mobile-phone studies: should we be concerned? Occup Environ Med.

Chien, L.N., Gittleman, H., Ostrom, Q.T., Hung, K.S., Sloan, A.E., Hsieh, Y.C., BarnholtzSloan, J.S., (2016). Comparative Brain and Central Nervous System Tumor Incidence and Survival between the United States and Taiwan Based on Population-Based Registry. Front Public Health, 4, 151.

Scarbrough, P.M., Akushevich, I.., Wrensch, M., \& Il'yasova, D., (2014). Exploring the association between melanoma and glioma risks. Ann Epidemiol, 24(6), 469-474.

Khan, A.A., Pandith, A.A., Wani, A.A., Malik, N.K., et al (2015). Significant Association of Proline Allele in TP53 Gene, Arg72pro Polymorphism in Brain Tumors and its Prognostic Value. Journal of Cancer Science \& Therapy Journal of Cancer Science \& Therapy. 7(7), 236-241.

Lannering, B., Sandstrom, P.E., Holm, S., et al (2009). Classification, incidence and survival analyses of children with CNS tumours diagnosed in Sweden 1984-2005. Acta Paediatr. 98(10), 1620-7.

Dolecek, T.A., Propp, J.M., Stroup, N.E., Kruchko C., (2012). CBTRUS statistical report: primary brain and central nervous system tumors diagnosed in the United States in 2005- 2009. Neuro-oncology; 14 Suppl 5, v1-49.

Kruiswijk, F., Labuschagne, C.F., Vousden, K.H., (2015). P53 in survival, death and metabolic health: a lifeguard with a licence to kill. Nat Rev Mol Cell Biol. 16, 393-405.
Yang, Z., Nie, S., Zhu, H., Wu, X., Jia, S., Luo, Y., Tang, W., (2013). Association of p53 Arg72Pro polymorphism with bladder cancer: a meta-analysis. Gene; 512(2), 408-13.

Dastjerdi, M.N., (2011). TP53 codon 72 polymorphism and P53 protein expression in colorectal cancer specimens in Isfahan. Acta Med Iran. 49, 71-77.

Hu, X., Zhang, Z., Ma, D., Huettner, P.C., Massad, L.S., Nguyen, L., Borecki, I., and Rader, J.S., (2010). TP53, MDM2, NQO1 and susceptibility to cervical cancer. Cancer Epidemiol Biomarkers Prev. 19, 755-761.

Sharma, S., Sambyal, V., Guleria, K., Manjari, M., et al (2014). TP53 Polymorphisms in Sporadic North Indian Breast Cancer Patients. Asian Pac J Cancer Prev. 15 (16), 6871-6879.

Zhuo, X.L., Cai, L., Xiang, Z.L., Zhuo, W.L., Wang, Y., Zhang, X.Y., (2009). TP53 codon 72 polymorphism contributes to nasopharyngeal cancer susceptibility: a meta-analysis. Arch Med Res. 40, 299-305.

Rogler, A., Rogenhofer, M., Borchardt, A., Lunz, J.C., Knoell, A., Hofstaedter, F., et al (2011). P53 codon 72 (Arg72Pro) polymorphism and prostate cancer risk: association between disease onset and proline genotype. Pathobiology: journal of immunopathology, molecular and cellular biology. 78, 193-200.

Lin, H.Y., Huang, C.H., Yu, T.J., Wu, W.J., Yang, M.C., Lung, F.W., (2012). P53 codon 72 polymorphism as a progression index for bladder cancer. Oncology reports. 27, 1193-9.

Qiao, Q., and Hu, W., (2013). The association between TP53 Arg72Pro polymorphism and lung cancer susceptibility: evidence from 30,038 subjects. Lung. 191, 369-77.

Rebbani, K., Marchio, A., Ezzikouri, S., Afifi, R., Kandil, M., Bahri, O., et al (2015). TP53 R72P polymorphism modulates DNA methylation in hepatocellular carcinoma. Mol Cancer. 14, 74.

Hossain, A., Murshid G.M.M., Zilani, M.N.H., Islam, F., Sultana, R., et al (2017). TP53 codon 72 polymorphism and breast cancer risk in Bangladeshi population. Breast Cancer 24, 571-578.

Liu P, Zhuo Z, Li W, Cheng J, Zhou H, et al (2019). TP53 rs1042522 C>G polymorphism and Wilms tumor susceptibility in Chinese children: a four-center case-control study. Biosci. Rep. 39, BSR20181891.

Bass, F, Bikker, H, Ommen, GJ and Vijlder, J (1984). Unusual scarcity of restriction site polymorphisms in human thyroglobin gene: A linkage study suggesting autosomal dominance of defective thyroglobin allele.Human genetics. 67, 301-305. 
Maniatis, T., Fritch, E.F., and Sambrook, J., (1982). Molecular cloning: A laboratory manual, Cold Spring Harbor Laboratory Press, New York.

Pinto, G.R., Yoshioka, F.K., Silva, R.L., Clara, C.A., et al (2008). Prognostic value of TP53 Pro47Ser and Arg72Pro single nucleotide polymorphisms and the susceptibility to gliomas in individuals from Southeast Brazil. Genet. Mol. Res. 7, 207-216.

Kirk, B.W., Feinsod, M., Favis, R., Kliman, R.M., et al (2002). Single nucleotide polymorphism seeking long term association with complex disease. Nucleic Acids Res. 30, 3295-3311.

-Peris-Bonet, R., Martinez-Garcia, C., Lacour, B., et al (2006). Childhood central nervous system tumours--incidence and survival in Europe (1978-1997): report from Automated Childhood Cancer Information System project. Eur J Cancer; 42(13), 2064-80.

Aydin, D., Feychting, M., Schüz, J., et al (2011). Impact of random and systematic recall errors and selection bias in case-control studies on mobile phone use and brain tumors in adolescents (CEFALO study). Bioelectromagnetics, 32, 396-407.

Hamajima, N., Matsuo, K., Suzuki, T., Nakamura, T., Matsuura, A., Hatooka, S., Shinoda, M., Kodera, Y., Yamamura, Y., Hirai, T., Kato, T., Tajima, K., (2002). No associations of p73 G4C14-to-A4T14 at exon 2 and p53 Arg72Pro polymorphisms with the risk of digestive tract cancers in Japanese. Canc. Lett., 181(1), 8185 .

Khadang, B., Fattahi, M.J., Talei, A., Dehaghani, A.S., Ghaderi, A., (2007). Polymorphism of TP53 codon 72 showed no association with breast cancer in Iranian women. Canc. Genet. Cytogenet. 173, 38-42.

Onrat, S.T., Ellidokuz, E., Kupelioglu, A., Durhan, E., (2009). Frequency of TP53 codon 72 polymorphism in cases with colon cancer. Turk. J. Canc., 39(1), 5-10.

Moradinasab, M., Ostovar, A., Nabipour, I., Eghbali, S.S., Vahdat, K., Ghaderi, A., Mohamad Reza Farzaneh, M.R., Ravanbod, M.R., (2017). TP53 Codon 72 Genetic Polymorphism, rs1042522, Modifies the Association Between Tobacco Smoking and Breast Cancer Risk.Iran Red Crescent Med J. 19(10), e58027.

Fang, Y., Wu, X., Lin Li, Zhu, J., Wu, H., Zhou, H., He, J., and Wang, Y., (2020). TP53 Arg72Pro polymorphism and neuroblastoma susceptibility in eastern Chinese children: a three-center case-control study. Biosci Rep. 40(5), BSR20200854.

Mammano, E., Belluco, C., Bonafe, M., Olivieri, F., Mugianesi, E., Barbi, C., Mishto, M., Cosci, M., Franceschi, C., Lise, M., Nitti, D., (2009). Association of p53 polymorphisms and colorectal cancer: Modulation of risk and progression. EJSO. 35(4), 415-419.

Zhu, Z.Z., Wang, A.Z., Jia, H.R., Jin, X.X., He, X.L., Hou, L.F., Zhu, G., (2007). Association of the TP53 Codon 72 Polymorphism with colorectal cancer in a Chinese population. Jpn. J. Clin. Oncol. 37(5), 385-390.

Doosti, A., Zamani, M., Dehkordi, P.G., Taheri, S., Banitalebi, M., and Mahmoudzadeh, M., (2011). Association of the p53 codon 72 polymorphism with colorectal cancer in South West of Iran. Scientific Research and Essays Vol. 6(15), 3148-3152. 